\title{
A Review on the Unpacking of Online learning Self-Efficacy Article by Shen, Cho, Tsai, \& Marra (2013)
}

\author{
Ervan Ibsahrodan \\ University of South Wales, Cardiff, United Kingdom \\ ervanibsahrodan@gmail.com
}

\begin{abstract}
ARTICLE HISTORY
Received : 20 February 2020

Revised : 26 February 2020

Accepted : 26 February 2020
\end{abstract}

\section{KEYWORDS}

Online Learning

Online Learning Experiences

Technology-Enhanced Learning (TEL)

Traditional Learning

Self-Efficacy

\begin{abstract}
The discourse of traditional versus online learning is not made distinct by the technological aspect only, but also the levels of students' self-efficacy. Self-efficacy is the ability to control and manage one's motivations, behaviour, and social environment to continue and consistently complete any tasks. This study aims to understand the discourse of online learning self-efficacy by reviewing a selected article due to its considerable influence in this specific body of work to this date. By using content analysis in a qualitative design, this study reviewed Shen, Cho, Chai, \& Marra's (2013) article entitled "Unpacking online learning experiences: Online learning self-efficacy and learning satisfaction." The results of this article are the comprehensive discussion of the article's strengths and weaknesses and the article's general context with the IMRAD framework.
\end{abstract}

\section{Introduction}

The process of learning has taken on new dimensions since the late $90 \mathrm{~s}$. No longer confined to formal classrooms where the students consist of children that are required by the nations and their parents to attend, classrooms nowadays are filled with students who voluntarily use their free time and even their wallets to learn. These classrooms are online classrooms, and the learning process is popularly known as online learning.

Historically, online learning in its essence existed since as far back as the $19^{\text {th }}$ century (Nicholson, 2007). Isacc Pitman taught writing skills his students via mail in 1840 . Harvard Professor Burrhus Frederic Skinner invented the teaching machine to enable schools to administer programmed instructions in 1954. It was in 1960 when the first computer-based training program was introduceddesigned for Illinois University students. Open University in Britain began to make online learning systems more interactive. It is then in 1999 when the term "e-learning" first started floating, and currently "virtual learning" and "online learning" are accepted as more accurate descriptions.

Online learning is different from traditional learning for reasons beyond the obvious technological aspect of the former. As mentioned before, online learning is unique in that it is mostly done by students who generally, purely voluntarily signed up for online classes without significant or immediate outside influences. Part of the appeal is that the students have considerably less issue with switching codes and receiving feedback online compared to face-toface classroom discourse (Derin \& Hamuddin, 2014; Herlinawati, 2014; Marwa, 2014). "Going online has not, however, proven to be a guarantee of growth and success for educational institutions," according to Anderson (2008), and it is also not a guarantee for students' to receive the maximum benefits of online learning. For one, fellow students themselves may hinder the learning progress by engaging in negative online behaviours such as cyberbullying (Hamuddin, Syahdan, Rahman, Rianita, \& Derin, 2019). Another reason would be one of the most popularly studied aspects of learning, namely the students' learning motivation. Traditional classes have the unique advantage of pushing students to communicate and cooperate with others as they are stuck in the same physical space. Thus students' can motivate each other in the learning process. This is not the case when it comes to online learning where students' mainly engage with the material and less with other people beyond screen-names.

With high interest on the second problem of online learning, this current study aims to understand online learning experiences concerning students' control of their motivation, behaviour, and social environment, in other words, their self-efficacy. As an initial foray to understand the discourse of people's experience with online learning, this current study attempts to review a selected article. The selected article is titled "Unpacking online learning experiences: Online learning self-efficacy and learning satisfaction" and it was published in 2013 in Volume 19 of the Journal of Internet and Higher Education in Elsevier. 
This selected article is the product of collaboration between four authors from different backgrounds relevant to online learning. The authors are Demei Shen from Shanghai Engineering Research Center in China, MoonHeum Cho from Lifespan Development and Educational Sciences in Kent State University in the United States (US), Chia-Lin Tsai from Psychological Sciences in MissouriColumbia University in the US, and Rose Marra, from Information Science and Learning Technologies in Missouri-Columbia University in the US. A brief search on their track record of research publication on Google Scholar revealed that they have a history of collaborating (Marra, Rogue, Rodgers, \& Shen, 2007; Marra, Edmister, Watford, Bogue, Tsai, \& Gooden, 2010) until at least three years later (Marra, Steege, Tsai, \& Tang, 2016).

This current study chose Shen, Cho, Chai, \& Marra's (2013) study because it has considerable influence in the body of knowledge on online learning. By $20^{\text {th }}$ February, this selected article has been cited by more than 150 studies, and at least five times by the most recent studies in 2020 . Alghamdi, Karpinski, Lepp, \& Barkley (2020) and Ruthotto, Kreth, Melkers, Stevens, \& Clare (2020) cited this article to note how self-efficacy beliefs and self-regulation should be in high levels for online learning success. It is cited by Lim, Jalil, Ma'rof, \& Saad (2020) that focused on blended learning. Krampah-Nkoom (2020) referred to it to evaluate employee's self-efficacy. Yavuzalp \& Bahçivan (2020) cited this article to produce the most recent online learning self-efficacy scale. It is quite apparent that this selected article is still relevant to this date.

\section{Method}

This current study aims to review a selected article that has been and is still a significant influence in the field of online learning. Due to this, the researcher designed the study to be qualitative and chose the method known as content analysis. This method is chosen because the data of this study is solely Shen, Cho, Chai, \& Marra (2013). Thus the results and discussion will be focused entirely on the content of the selected article. The methodological framework of this study is depicted in Figure 2.1.

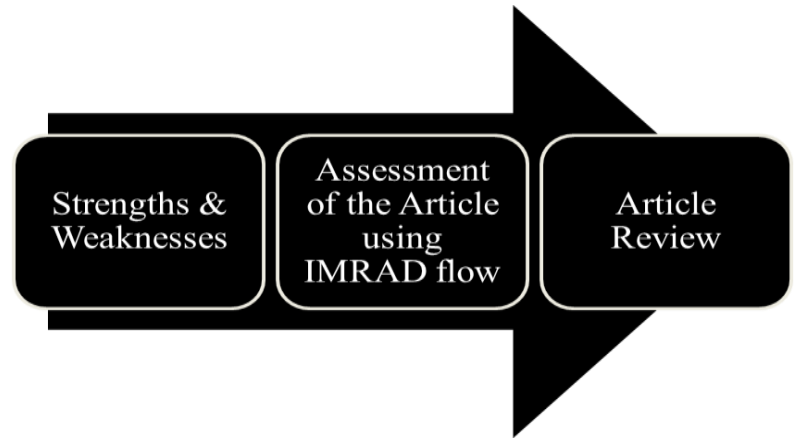

Figure 2.1 Framework of the Method
The way the researcher approached this study is purely qualitative, relying on the researcher's understandings and opinions. First, this study presented the strengths and weaknesses of the article. Second, this study discussed the contents of the article in a coherent manner based on IMRAD, i.e. introduction, method, results, analysis, and discussion. IMRAD is the backbone of any decent research article and the researcher felt the selected article would be understood much better by using IMRAD as the "analysis framework." By going through these two steps, the researcher produced this current article review.

\section{Results \& Discussion}

\subsection{Strengths and Weaknesses of the Article}

This article discusses self-efficacy for online learning and learning satisfaction. Judging from the various references regarding the notion of self-efficacy, it is the beliefs of an individual in achieving success in what they do. Self-efficacy itself is the key to the success of online learning, which can determine the level of student motivation in using ICT in the learning process. In addition, the term of self-efficacy, if someone has a low level of selfefficacy, then the person also has little to achieve. Selfefficacy is also a reference or benchmark in predicting student learning satisfaction in using ICT in the millennial era.

In writing a research article, it indeed cannot be separated from the strengths and weaknesses as it is known that the quality of an article can be seen from the contents of the article. Whether the article has many advantages or not. Because the strengths of an article would be a plus and support the article itself to be published in journals with decent accreditation, even articles that have been published in journals are mutated and indexed, not escape the negligence of researchers when writing their research findings. Here are the advantages and disadvantages found when reviewing this article.

First, this review article will discuss the advantages first. They are starting from writing abstracts that have fulfilled the elements of IMRAD (Introduction, Method, Results and Discussion). The author writes briefly and clearly about what self-efficacy is and the importance of it in online learning among students-followed by mentioning their purpose of researching this study which is to identify the dimensions of online learning self-efficacy. The authors also explain what methods are used in conducting the research to find the results of their study, namely exploratory factor analysis. And finally, the authors wrote the results and discussion briefly and obviously that online learning self-efficacy can predict students' online learning satisfaction. That way, the abstract written by the authors can be said to be complete and straightforward. 
In the introduction, the authors divide into several essential points. They raise the background of self-efficacy as something that is challenging among students who use ICT in online learning. When viewed from the content, the authors provide a good breakdown of the discussion about self-efficacy. Variations of citations from experts are beneficial and support the arguments they wrote. In each paragraph, the authors cited and quoted statements from more than one references which reinforces their argument so that the writing of the article has a novelty.

The author also discusses the literature review in the form of previous research that relates to the topic of selfefficacy. The author mentions several numerous studies that have been conducted, including McGhee in 2010 who found a positive and significant relationship between technological self-efficacy and academic achievement of 45 community college students. Then there was Thompson and Lynch in 2003 who examined the psychological processes underlying resistance to WBI and stated that students with low internet self-efficacy tended to resist WBI. Ergul in 2004 found self-efficacy in distance education to significantly estimate student achievement levels. Besides, Artino in 2008 found that students having self-efficacy based on computer learning were more likely to experience learning satisfaction than students with low self-efficacy. Therefore, the authors have many references when conducting this research.

Broadly, the authors described their explanations very well; both in terms of explaining and arguing which are always supported and strengthened by quotations from experts and other authors who also have already researched online learning self-efficacy in students. The author does not forget to explain the points about what variables support their research. Among these are prior online experience, gender, and student satisfaction with online learning. This article also contains research questions which are the focus of the authors in finding the results of the research itself. Their focus in researching this time are the dimensions of online learning self-efficacy, what variables are related to the study's online learning self-efficacy and to what extent is self-efficacy related to student online learning satisfaction.

In methodology, the authors describe several points, namely participants, measures, demographic variables, online learning self-efficacy, learning satisfaction and procedures. At the participant point, the authors explained that there were 406 online students participated in this study, so this number could be said to represent the existing population. The measure points explain what instruments are used to indicate findings. Demographic variables in which students who participated were asked to self-report such as genders, academic status and online course number taken. At the point of online learning self-efficacy, the authors developed a new scale to measure students' online learning self-efficacy based on a literature view which conceptualized into six types of self-efficacy; (a) Self- efficacy to complete an online course, (b) self-efficacy to interact with classmates, (c) self-efficacy to interact with an instructor, (d) self-efficacy to self-regulate in online learning, (e) self-efficacy to handle a course management system, (f) self-efficacy to socialize with classmates. Learning satisfaction points were measured with five items of scale 1 to 5 , where 1 is "strongly disagree", and 5 is "strongly agree" adapted from Lins research in 2005. The last is the procedure, explaining the steps taken by researchers in collecting data obtained from two universities in Midwestern, US. The authors contacted online instructors and asked for permission to carry out the study in online courses. After securing approval to research, the authors post a recruitment letter and a link to the online survey. After students fill out the online consent form, they are directed to fill out an online survey on the website. These six points have specific explanations and can be understood by the readers.

In the results section, when the writer presents his findings, the writer is based on research questions, this also makes it easier for readers to get information and answers from research questions and is equipped with proper decomposition. The author presents data in the form of a varied and accurate table. Among exploratory factor analysis, descriptive statistics of varieties and multiple regression analysis for learning statistics, and each table is equipped with a clear explanation - processing data using IMB SPSS statistics 20 so that the data obtained can be trusted and accurate.

In the conclusion section, the authors explain about their findings, that they explore five aspects of self-efficacy that may represent more concrete online learning contexts and this is different from previous studies that only examine one or two aspects. That way, of course, their findings are far more specific when looking at the references used are also more than 10 sources. Overall, this article is excellent and enough to make readers understand and get points from what they want to convey.

Even so, this article did not escape weaknesses. Although not too many, the weaknesses that are seen cause this article to be less good. The following weaknesses were found when reviewing this article. This article has a few paragraphs that should be able to add value to this article to make it look good. Because each of the points described only has one or two paragraphs, so the explanation given seems only fleeting and does not seem to provide further information to the reader. Especially in the methodology section, the explanation given is not detailed. What method is used is not explained comprehensively and straightforwardly. For example, in the points of measures and learning satisfaction, only explain in less than one paragraph. The instrument used is also unclear; the writer should be able to explain what instruments are used in this study in more detail so that readers are not confused. Likewise, the techniques and steps of data retrieval are also not explained entirely. 


\subsection{Overview of the Article}

Demei Shen, Moon-Heum Cho, Chia-Lin Tsai, and Rose Marra published an article titled "Unpacking online learning experiences: Online learning self-efficacy and learning satisfaction" in 2013 on Journal of Internet and Higher Education. The authors presented how their research is especially contributive for the field of technologyenhanced learning by poking on a significant gap in the research of online learning self-efficacy. Noting on how previous studies on the topic have mainly focused on computer self-efficacy, this particular article shed light on how online learning self-efficacy has multiple dimensions that have not been explored. Conscious of the significance of self-efficacy as a key component in successful online learning, Shen, Cho, Chai, \& Marra (2013) identified as many as five dimensions of online learning self-efficacy.

In the introduction, the authors explained multiple times how their research contributes to the literature of online learning self-efficacy, although the explanations were somewhat short to illustrate past research as well as the problem fully. Firstly, the authors only briefly mentioned the fact that the drop-out rate of online learning is higher than traditional learning is related to self-efficacy, then quickly concluding that the latter is critical for the reduction of drop-out rate. The authors then pointed out how past studies leaned heavily on only one aspect of self-efficacy in online learning settings, which is the technological aspect. Thus the neglected two other areas, i.e. learning and social interaction, will be tackled by their research alongside with the third in a comprehensive manner. Their study will also address the contradicting existing opinions regarding the influence of prior online experience and gender of online learners, pointing out that empirical study on those are needed and will be tackled by their research.

The literature review of the article showed that the authors were clearly trying to tackle multiple aspects that were research gaps of the literature, but close attention on the studies cited in the paragraphs indicated that the amount of literature the article used to point out the gaps were rather sparse. In defining self-efficacy, the authors quoted a rather old source by Bandura (1986) and only used one source (Schunk, 1991) to state that previous multiple studies have demonstrated the crucial nature of self-efficacy as a predictor of academic achievement. Furthermore, selfefficacy was stated as "a better predictor than any other cognitive or affective processes" (p.1), but the latter was never elaborated. Most of the studies cited as references for the literature review of this 2013 article were from the last 10 years, but there were only one or two studies cited on each point before the authors claimed that there were little existing studies on those points. While it may be true, it seemed stark compared to the paragraph on gender and selfefficacy (p.2), which was much more thorough than the other paragraphs of the literature review. At the very least, the authors were not biased with the concepts discussed and concisely developed their research questions.
The method section in the article seemed dry, as they stopped short of explaining the participants, the demographic variables, the measures, the scales, and the procedure without reiterating the article's main aim. The authors did not specify the method of sampling but did clearly describe the participants involved in the research, which are "students who were enrolled in an online course" (p.2). The sample was dominantly female by almost 3 out of 4, so it may not completely address the gender influence aspect of the research. The online course that the sample was taken from was also never described, so there was no concrete justification on why these participants were chosen, though it may be of convenience as the procedure section of the method mentioned that the data were collected from two Midwestern United States universities. All 406 online students were characterized impressively through a table of description denoting their gender, ethnicity, and degree. The 6 types of scale of self-efficacy that the authors developed was justified thoroughly following the literature review, each item evaluated by experts and revised by the research group. Compared to these last two items, the measures and demographic variables were less developed in the article as they were explained very little.

Concerning the outcome, while the article did not explicitly state that it is quantitatively-based, the results made it obvious. By going through each research question in order, the article mentioned the types of analysis that the study uses, why those specific analyses were used and the numerical results of the analyses. For the first research question, the article stated both exploratory factor analysis and Kaiser-Meyer-Olkin measure identified the adequacy of sampling, suggesting give factors of online learning selfefficacy, i.e. completing, handling tools, interacting with instructors, interacting with classmates, and interacting with classmates specifically for academic purposes. The second research question seems to be the article's major finding, considering the table displaying the complete results of the descriptive statistics. This question on the variables related to self-efficacy also seems to receive the most attention by the authors, as the article showed as many as seven minor headings. The third research question intends to find out the extent of how self-efficacy is related to students' online learning satisfaction, which the authors found out through only multiple regression analysis.

The article discussed on how online learning selfefficacy is indeed multidimensional, containing as many as five dimensions that future research should address in the context of all three aspects of online learning. The question on gender as a variable was answered as a significant predictor. The question on online experience was identified into two beliefs, i.e. self-efficacy, to complete an online course and to interact with classmates for academic purposes. The question on academic status was found to be unrelated with most dimensions, agreeing with past studies, meaning that self-efficacy of an online learner cannot be differentiated between being an undergrad or a grad student. 
Finally, the authors had gone the extra mile of providing how their results may impact the conduct of future online teaching. The five dimensions the article identified could support students' participation in online learning, promote their social interaction with both instructors and classmates that are having difficulties, enhance students' self-efficacy to utilize the tools provided in online learning courses, and perhaps nudge the customization of online courses towards different genders. By ending this article with a conclusion that summarizes the many contributions this research has done, the researcher believes that this article deserves its place in the Q1 Journal.

\section{Conclusion}

The researcher considers the article's display of results may need to be filtered into other types of displays that are more familiar for regular readers or at least described qualitatively rather than purely pointing out the quantitative results. However, the researcher thinks that it does not negate this article's greatest strength, which is the way the authors developed the scale to measure students' online learning self-efficacy, as it was concise and highly clear to be replicated by future studies. The complicated display of results also does not retract readers' understanding of the outcome of the research, as the discussion was thorough, and the conclusion was concise. Overall, the authors solidified its position as a major contribution to the literature of online learning self-efficacy by answering their research questions born from the existing research gaps they have identified from the literature review.

\section{Acknowledgement}

The author expresses his gratitude to Unilak-Research Advancement for Intellectual and Scientific Empowerment (U-RAISE) Academy for their contribution and engagement in the discussions focused on analysing this article. Note, the contents of this article are of the researcher's understanding and does not reflect the variety of opinions of the researchers of U-RAISE Academy.

\section{References}

Alghamdi, A., Karpinski, A. C., Lepp, A., \& Barkley, J. (2020). Online and face-to-face classroom multitasking and academic performance: Moderated mediation with self-efficacy for self-regulated learning and gender. Computers in Human Behavior, 102, 214-222.

Anderson, T. (Ed.). (2008). The theory and practice of online learning. Athabasca University Press.

Bandura, A. (1986). Social foundations of thought and action. Englewood Cliffs, NJ: Prentice-Hall.

Derin, T., \& Hamuddin, B. (2019). Foreign Language Classroom Anxiety, and Enjoyment During Study Abroad: A Review of Selected Paper. Lisan: Jurnal Bahasa dan Linguistik, 8(2), 76-82.
Derin, T., Deliani, S., Fauziah, N., Afifah, N., \& Hamuddin, B. (2019). Indonesians' Tendency to Refer Abbreviation as Acronym: Types of Abbreviation as Word Formation Process. Globish: An EnglishIndonesian Journal for English, Education, and Culture, 8(2).

Hamuddin, B., Syahdan, S., Rahman, F., Rianita, D., \& Derin, T. (2019). Do They Truly Intend to Harm Their Friends?: The Motives Beyond Cyberbullying among University Students. International Journal of Cyber Behavior, Psychology and Learning (IJCBPL), 9(4), 32-44.

Herlinawati. (2014). Feedback in English Writing for Indonesian EFL Students. ELT-Lectura, 1(1).

Krampah-Nkoom, A. (2020). Evaluating the effects of Online training on Employee Self Efficacy. A Dilemma from the Banking Industry in Ghana. Journal of Arts and Humanities, 9(2).

Lim, C. L., Ab Jalil, H., Ma'rof, A. M., \& Saad, W. Z. (2020). Peer Learning, Self-Regulated Learning and Academic Achievement in Blended Learning Courses: A Structural Equation Modeling Approach. International Journal of Emerging Technologies in Learning (iJET), 15(03), 110-125.

Marra, R. M., Steege, L., Tsai, C. L., \& Tang, N. E. (2016). Beyond "group work": an integrated approach to support collaboration in engineering education. International Journal of STEM Education, 3(1), 17.

Marra, R., Bogue, B., Rodgers, K., \& Shen, D. (2007). Selfefficacy of women engineering students? Three years of data at US institutions. In Proceedings of the 2007 ASEE Annual Conference and Exposition, Honolulu, $H I$.

Marra, R., Edmister, W., Watford, B., Bogue, B., Tsai, C. L., \& Gooden, F. (2010). Peer Mentoring: Impact on Mentees and Comparison with Non-Participants. In American Society for Engineering Education. American Society for Engineering Education.

Marwa, M. (2014). Reasons for Students' Code-Switching Between Informal Indonesian and English in ELT Contexts. ELT-Lectura, 1(1).

Nicholson, P. (2007). A history of e-learning. In Computers and education (pp. 1-11). Springer, Dordrecht.

Ruthotto, I., Kreth, Q., Melkers, J., Stevens, J., \& Clare, T. (2020). Lurking and participation in the virtual classroom: The effects of gender, race, and age among graduate students in computer science. Computers \& Education, 103854.

Schunk, D. H. (1991). Self-efficacy and academic motivation. Educational Psychologist, 26, 207-231. 
Shen, D., Cho, M. H., Tsai, C. L., \& Marra, R. (2013). Unpacking online learning experiences: Online learning self-efficacy and learning satisfaction. The Internet and Higher Education, 19, 10-17.

Yavuzalp, N., \& Bahçivan, E. (2020). The Online Learning Self-Efficacy Scale: Its Adaptation into Turkish and Interpretation According to Various Variables. Turkish Online Journal of Distance Education, 21(1), 31-44. 